\title{
Plasma concentrations of progesterone in female red deer (Cervus elaphus) during the breeding season, pregnancy and anoestrus
}

\author{
C. L. Adam, C. E. Moir and T. Atkinson \\ Rowett Research Institute, Bucksburn, Aberdeen AB2 9SB, U.K.
}

\begin{abstract}
Summary. Concentrations of progesterone in peripheral plasma of red deer hinds were basal $(<1 \mathrm{ng} / \mathrm{ml})$ during lactation/seasonal anoestrus, but increased abruptly at the onset of the breeding season. Lactating hinds $(\mathrm{N}=19)$ started ovarian cycles 10 days later $(P<0.01)$ and conceived 16 days later $(P<0.001)$ than did 13 weaned hinds. There was no evidence, from plasma progesterone values, of silent oestrus at the start of the season. Progestagen/PMSG treatment induced early ovulations in 8 anoestrous hinds but fertility was low, only 2 conceiving and giving birth. Pregnant hinds $(\mathrm{N}=42)$ had high plasma concentrations of progesterone (mean $3-5 \mathrm{ng} / \mathrm{ml}$ ) which declined just before parturition.
\end{abstract}

\section{Introduction}

Progesterone plays an important role in the regulation of the oestrous cycle and in the maintenance of pregnancy in the ewe. Plasma concentrations of progesterone can be used to assess current reproductive status and are likely to be useful in the study of reproduction in the female red deer (Cervus elaphus) which is also seasonally polyoestrous. However, to date there is little published information on 'normal' values for deer (Kelly, McNatty, Moore, Ross \& Gibb, 1982). Oestrous cyclicity begins in October and continues until March if pregnancy does not occur (Guinness, Lincoln \& Short, 1971). For wild hinds lactating during the rut there is some evidence of reduced fertility (Guinness, Albon \& Clutton-Brock, 1978) and later conception dates (Mitchell \& Lincoln, 1973) compared with non-lactating hinds, but this generally relates to their poorer body condition. Out-of-season breeding is readily induced in the ewe by progestagen/PMSG treatment, but it is not known whether this treatment, which can increase ovulation rate during the breeding season (Kelly et al., 1982), can induce early breeding in anoestrous hinds.

In the present work we examined temporal variations in the concentrations of progesterone in peripheral plasma of farmed red deer hinds during the breeding season, pregnancy and seasonal anoestrus. The dates of onset of the breeding season were compared between hinds that had been weaned and those that were still lactating, and a preliminary trial was undertaken to investigate the response of anoestrous hinds to progestagen/PMSG administration in an attempt to advance the breeding season.

\section{Materials and Methods}

Breeding season. Forty (40) red deer hinds, aged 2 or 3 years, all of which had produced a calf in the previous June, had blood samples taken on Monday, Wednesday and Friday or on Monday and Thursday of each week from 1 September to 17 November 1982. Initial live weight was $90 \pm 7.9$ (mean \pm s.d.) $\mathrm{kg}$ and further live weight measurements were taken every 2 weeks. In the first part of the study 13 hinds were weaned from their calves (Group W) on 1 September and 19 hinds 
continued to suckle their young (Group L) until 4 November. The two groups, each with a single stag which was known to be fertile from his performance in previous years, grazed in separate paddocks on similar pasture until 27 October. Thereafter the groups were mixed. In addition, a further 4 weaned hinds (Group WI) and 4 lactating hinds (Group LI), which were running with the respective Groups $W$ and $L$, each had an intravaginal sponge containing $30 \mathrm{mg}$ fluorogestone acetate (Chronogest: Intervet Ltd, Cambridge, U.K.) inserted on 1 September for 12 days. Each hind was given an intramuscular injection of 500 i.u. PMSG (Folligon: Intervet) at sponge withdrawal and kept away from the stag for $48 \mathrm{~h}$. On 27 or 28 September their ovaries, and those of 5 untreated hinds taken from Groups $\mathrm{W}$ and $\mathrm{L}$ (controls), were examined by laparoscopy to determine numbers of corpora lutea.

Pregnancy. From November 1981, after the rut, to August 1982, after the calving period, blood samples were taken every $2-4$ weeks from 42 pregnant hinds (which included the 40 used in the trial reported above) and 1 non-pregnant hind. The deer grazed lowground pasture during the spring and summer, and received hay and concentrates outdoors during the winter.

Blood sampling and hormone assay. Blood samples were taken by jugular venepuncture into heparinized vacutainer tubes, centrifuged, and the plasma fractions stored at $-20^{\circ} \mathrm{C}$ until analysed for progesterone.

Progesterone concentrations in plasma were measured by a modification of the radioimmunoassay method of Henricks, Dickey \& Hill (1971), as described previously (Adam \& Atkinson, 1984). The antiserum (HP/S/53-IIC from Guildhay Antisera, University of Surrey, U.K.) was raised in sheep to progesterone-11 $\alpha$-hemisuccinate-ovalbumen and cross-reactions were $0.3 \%$ with 17 hydroxyprogesterone, $0.8 \%$ with corticosterone, $0.9 \%$ with deoxycorticosterone and negligible for other steroids tested. Intra- and inter-assay coefficients of variation were 9 and $13 \%$ respectively. The sensitivity of the assay was $0.2 \mathrm{ng} / \mathrm{ml}$.

Statistical procedure. For statistical evaluation data were analysed by Student's $t$ tests.

\section{Results}

\section{Breeding season}

Hinds in Groups W and $L$ had a final live weight of $88 \pm 7 \cdot 1$ (mean \pm s.d.) $\mathrm{kg}$ in November.

Study 1 . All hinds had very low plasma concentrations of progesterone $(<1 \mathrm{ng} / \mathrm{ml})$ at the start of the sampling period, which continued until the estimated first ovulation of the breeding season. The first ovulation was judged to have occurred on the day that was immediately followed by an increase in plasma progesterone above $1 \mathrm{ng} / \mathrm{ml}$ which was sustained for several days or more. The average pattern of plasma progesterone concentrations during the transition from anoestrus to the onset of breeding activity is shown in Text-fig. 1. Some individual deer in both groups showed a slight 1-3-day rise in plasma progesterone to $1-2 \mathrm{ng} / \mathrm{ml}, 2-7$ days before $(\mathrm{N}=10)$ or about 30 days before $(\mathbf{N}=3)$ their first estimated ovulation. In general, however, the first rise above $1 \mathrm{ng} / \mathrm{ml}$ was that seen immediately after the estimated first ovulation. If the days of the year are numbered consecutively from 1 January for statistical purposes, the mean date ( \pm s.e.m.) of estimated first ovulation was Day $281 \pm 2.8$ (8 October) for Group W hinds, earlier than that for Group L hinds, Day $291 \pm 2.2$ (18 October) $(P<0.01)$. Overt oestrous behaviour and/or matings were rarely seen but all 13 Group W hinds evidently conceived at this first ovulation, as indicated by the subsequent high plasma progesterone values sustained throughout the sampling period and confirmed by the subsequent interval to calving. However, while 14 of the 19 Group L hinds also mated successfully at the first ovulation, 5 returned to oestrus as shown by a subsequent drop and rise again in plasma progesterone concentration. The mean conception date ( \pm s.e.m.) for Group L hinds, Day $297 \pm 2.9$ (24 October), was therefore considerably later than that for Group W hinds, Day $281 \pm 2.8$ (8 October) $(P<0.001)$. 


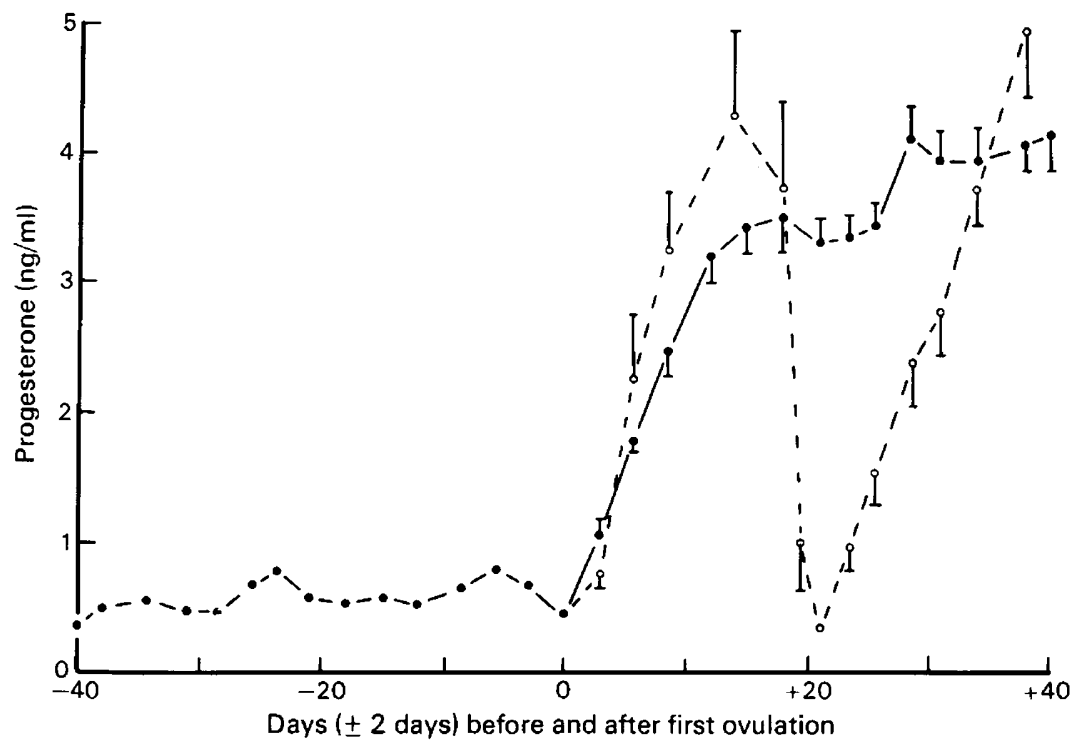

Text-fig. 1. Mean progesterone concentration (with associated 1 s.e.m., where s.e.m. $\geqslant 0 \cdot 1$ ) in the peripheral plasma of hinds during the transition from anoestrus to breeding activity. Data for all deer $(\mathrm{N}=32)$ are included before the first ovulation. Thereafter, mean values are given separately for deer that conceived at the first ovulation $(\mathrm{N}=27 ; \mathrm{O})$ and those that returned to oestrus after one oestrous cycle $(\mathrm{N}=4, \mathrm{O})$, excluding the deer $(\mathrm{N}=1)$ that returned to oestrus after prolonged elevation of plasma progesterone.

Of the 5 Group L hinds that did not conceive at the first ovulation, one hind showed a prolonged elevation of plasma progesterone ( 35 days), whereas 4 hinds had plasma progesterone concentrations elevated for a shorter period, before they dropped below $1 \mathrm{ng} / \mathrm{ml}$ and rose for a second time. This was perhaps indicative of the luteal phase of a single oestrous cycle but the effect of mating and pregnancy (however short) cannot be ruled out. The average cycle length ( \pm s.e.m.) from first to second ovulation for these 4 hinds was $21 \pm 1 \cdot 3$ days, with a peak plasma progesterone value of $4.5 \pm 0.43 \mathrm{ng} / \mathrm{ml}$ after $14 \pm 0.8$ days. The drop in plasma progesterone below $1 \mathrm{ng} / \mathrm{ml}$, indicative of the period of second oestrus and ovulation, lasted about 4 days, showing a distinct trough: ovulation was deemed to have occurred on the day when plasma progesterone was at its lowest value. All 5 hinds conceived successfully at their second ovulation as indicated by the subsequently sustained high concentration of progesterone in their plasma, and confirmed by the interval to calving.

All 32 hinds produced calves in the following year during the period 12 May to $7 \mathrm{July}$, and the mean duration of gestation ( \pm s.e.m.) was $234 \pm 0.5$ days.

Study 2. All 8 PMSG-treated hinds apparently ovulated 2-4 days after injection, i.e. on about 16 September, or Day $259 \pm 0 \cdot 3$ (s.e.m.), significantly earlier in the year than the first ovulations of all untreated hinds in Study $1(P<0.001)$. Evidence of ovulation was provided by plasma progesterone profiles (Text-fig. 2) and by laparoscopic examination of the ovaries 14-15 days after the PMSG treatment. Two hinds (one each from Groups WI and LI) each had 3 corpora lutea whereas the remaining 6 hinds had had single ovulations. By contrast, none of the ovaries of the 5 control hinds examined by laparoscopy had a corpus luteum, indicating natural anoestrus. From Text-fig. 2 it is seen that the 2 superovulating hinds ( $A$ and $E$ ) conceived at the first oestrus, although overt oestrous behaviour and mating was only witnessed in one. Of the remaining 6 hinds, after a short period with elevated plasma progesterone indicative of the luteal phase of the induced oestrous cycle, 2 Group WI hinds and 1 Group LI hind returned to oestrus and mated successfully (B, $_{0}$, Cond $_{2}$ 


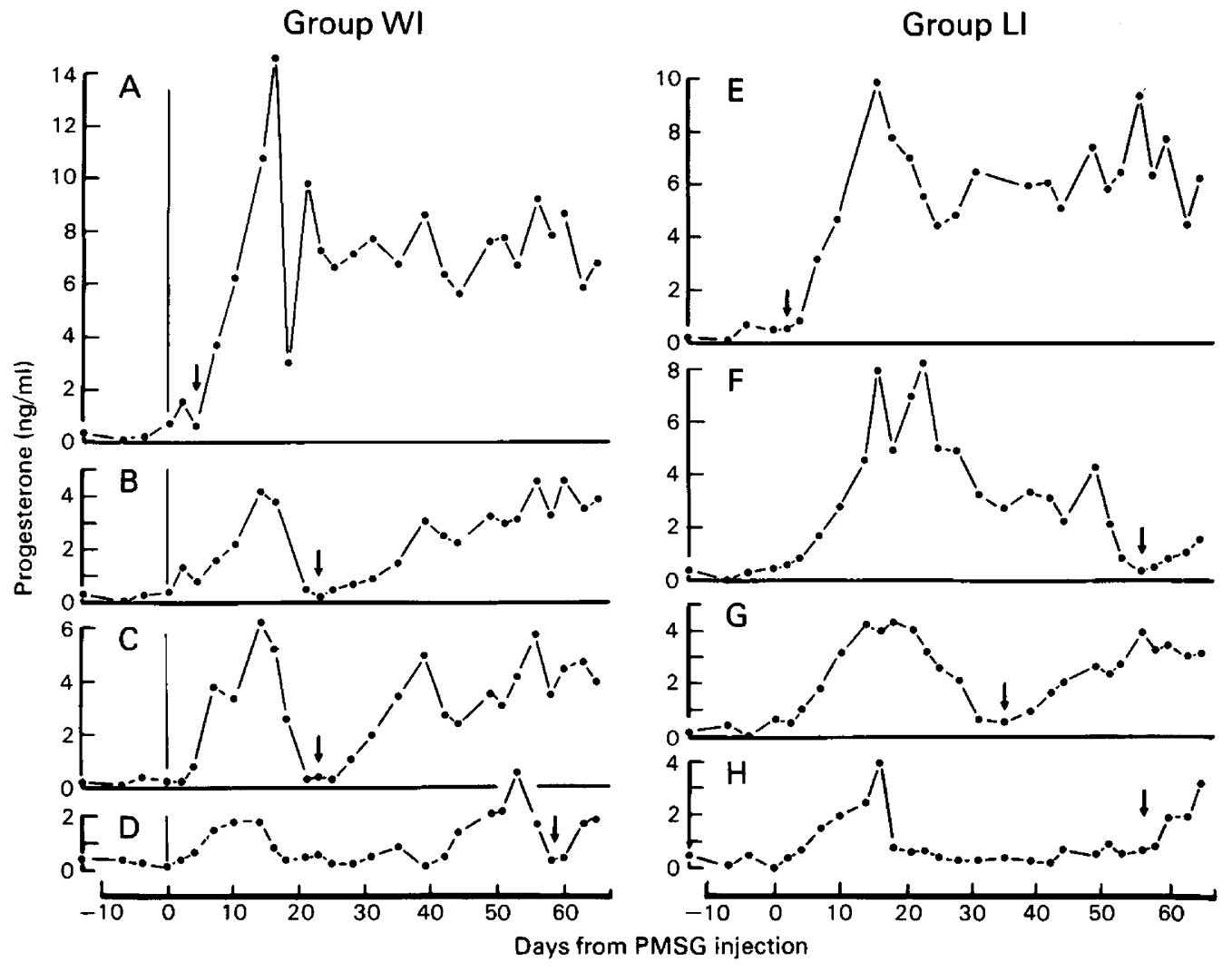

Text-fig. 2. Plasma progesterone profiles of weaned (Group WI) and lactating (Group LI) hinds injected i.m. with 500 i.u. PMSG after intravaginal progestagen treatment. An arrow denotes successful mating. Hinds $A$ and $E$ each had 3 corpora lutea after treatment and Hinds B, C, D, F, G and $\mathrm{H}$ each had 1 corpus luteum.

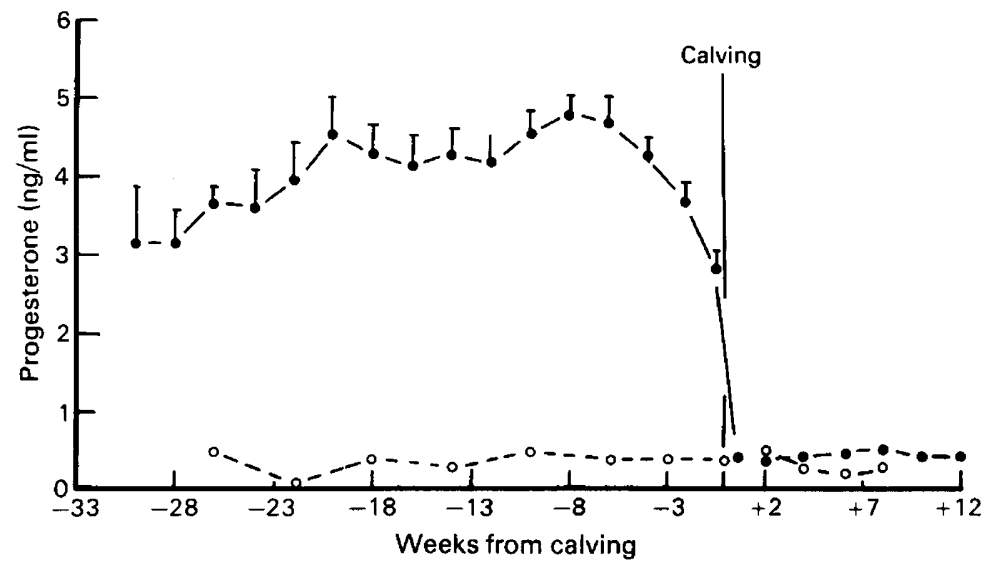

Text-fig. 3. Mean progesterone concentration (with associated 1 s.e.m.) in the plasma of 42 pregnant red deer hinds $(O)$. Values are also shown for one non-pregnant hind sampled over the same time period $(\mathrm{O})$. 
G), but 1 hind in each group reverted to anoestrus (D and H). One hind in Group LI returned to oestrus, and mated, after a more prolonged elevation of plasma progesterone values $(F)$.

All 8 deer were pregnant by the end of the sampling period. The 6 singletons were born after a gestation of $236 \pm 1.0$ (s.e.m.) days. One of the 2 hinds with 3 corpora lutea aborted triplets after 226 days and the other gave birth to twins of very different birth weights (only the larger one of which survived) after 242 days. Calving dates were similar to those of untreated hinds, between 17 May and 10 July.

\section{Pregnancy}

Stage of pregnancy was determined by back-dating from calving date for each hind. Plasma concentrations of progesterone remained high $(>3 \mathrm{ng} / \mathrm{ml})$ in the 42 hinds throughout pregnancy and only fell during the last 4 weeks before calving to reach basal levels at the start of lactation (Text-fig. 3). The single non-pregnant, non-lactating hind exhibited basal concentrations $(0 \cdot 3-0 \cdot 5$ $\mathrm{ng} / \mathrm{ml}$ ) on all sampling dates.

\section{Discussion}

Concentrations of progesterone in peripheral plasma of red deer hinds evidently provide valuable information about reproductive status. In the present study, after parturition in the summer, or after the end of the period of oestrous cyclicity for deer failing to conceive, and before the breeding season in the autumn, anoestrus was characterized by basal values of progesterone in the circulating plasma, usually about $0.5 \mathrm{ng} / \mathrm{ml}$ and always below $1.0 \mathrm{ng} / \mathrm{ml}$. Resumption of breeding activity was indicated by a sharp rise in plasma progesterone to concentrations over 3-4 $\mathrm{ng} / \mathrm{ml}$ immediately following the first ovulation. Without constant observation, oestrus often passes undetected in the hind, but the plasma progesterone values gave unequivocal evidence of the occurrence of ovulation and oestrous cyclicity. It is clear that most deer in the present study mated at their first ovulation of the breeding season and that, unlike the sheep (Walton, McNeilly, McNeilly \& Cunningham, 1977) and in agreement with observations on deer by Guinness et al. (1971), they had not previously shown silent oestrus with ovulation. Weaned hinds (Group W) not only had their first ovulation earlier than did lactating hinds (Group L) $(P<0.01)$, but also all conceived at this time. Conception dates were further delayed for lactating hinds $(P<0 \cdot 001)$. This was unlikely to have been a body condition effect (as noted for wild deer by Mitchell \& Lincoln, 1973) because all the hinds were in good condition at the start and showed insignificant weight loss during the trial. Fertility in terms of calving percentage was not impaired by lactation during the rut (in contrast to observations by Guinness et al., 1978) and all hinds produced calves the following year. The common farm practice of weaning hinds before the rut to improve fertility may therefore be unnecessary when adequate nutrition is provided, but resulting calving dates may indeed be earlier.

The mean gestation length of 234 days was similar to that of previous reports (231 days: Guinness et al., 1971; 233 days: Kelly \& Moore, 1977) and therefore the calving dates themselves provided additional evidence for ovulation, oestrus and mating dates derived from plasma progesterone data.

The pattern of progesterone concentrations in plasma after the estimated first ovulation shown by 4 of the 5 lactating hinds which returned to oestrus match closely those of 8 non-lactating hinds which cycled 1-3 times at the start of the breeding season in another trial reported elsewhere (Adam \& Atkinson, 1984). The cycle length of 21 days is slightly longer than the 18-day cycles reported elsewhere (Guinness et al., 1971; Kelly \& Moore, 1977). As seen in other farmed ungulates, plasma progesterone is low at oestrus and ovulation, indistinguishable from anoestrous levels, rises to a peak luteal-phase value and thereafter declines more rapidly to reach basal levels at the next oestrus 
and ovulation. In the pregnant hind plasma progesterone concentrations do not fall after reaching the peak value. In a plasma sample taken during the winter months, the progesterone concentration of the pregnant hind is indistinguishable from that of the luteal phase of a non-pregnant hind which can continue to exhibit oestrous cycles until March (Guinness et al., 1971).

The present preliminary study has shown that progestagen/PMSG treatment is able to induce oestrus in hinds, whether lactating or not, during their natural seasonal anoestrus. However, the response was variable and fertility at the induced oestrus was apparently low (in agreement with Kelly et al., 1982) since only $2 / 8$ successfully mated at this time, although all hinds apparently ovulated, and actual calving dates were not advanced by treatment. Fertility, however, could have been affected by the laparoscopy procedure and by the separation from stags until $48 \mathrm{~h}$ after sponge withdrawal. Unlike melatonin administration (as reported by Adam \& Atkinson, 1984), the treatment evidently did not reliably initiate continued oestrous cyclicity, as only $3 / 8$ returned to oestrus and a second ovulation. As in the study by Kelly et al. (1982), PMSG induced some multiple ovulations but the worst consequence of this was made apparent by the subsequently aborted triplets. Natural twinning is extremely rare in red deer, but this trial demonstrated that it is possible for a hind to carry twin calves to term, and the feasibility of increasing birth rate by induced twinning merits further investigation.

In the present study, progesterone concentrations in plasma remained high and relatively constant throughout pregnancy, in agreement with the data of Kelly et al. (1982). This is in contrast to the sheep in which plasma progesterone values are similar in early pregnancy to those in deer, but rise further 2-5-fold in the middle and last thirds of pregnancy (Bassett, Oxborrow, Smith \& Thorburn, 1969). However, like the ewe, the hinds showed a marked decrease in plasma progesterone in the 1-4 weeks preceding parturition. Kelly et al. (1982) concluded that luteal tissue provides most, if not all, the progesterone during pregnancy. In addition to the larger primary corpus luteum, an accessory corpus luteum is often present in the pregnant red deer (Guinness et al., 1971 ; Kelly \& Challies, 1978). However, its role is obscure as pregnancy is adequately maintained with or without this luteal body. It may be an additional source of progesterone contributing to the plasma values observed, but its presence or absence in the present study was not clearly detectable from these values alone.

We thank Mr K. Rae and Mr R. Greenaway for assistance with animal handling and management, and Mr M. Phillippo for the laparoscopy examinations.

\section{References}

Adam, C.L. \& Atkinson, T. (1984) Effect of feeding melatonin to red deer (Cervus elaphus) on the onset of the breeding season. J. Reprod. Fert. 72, 463-466.

Bassett, J.M., Oxborrow, T.J., Smith, I.D. \& Thorburn, G.D. (1969) The concentration of progesterone in the peripheral plasma of the pregnant ewe. $J$. Endocr. 45 , 449-457

Guinness, F., Lincoln, G.A. \& Short, R.V. (1971) The reproductive cycle of the female red deer, Cervus elaphus L. J. Reprod. Fert. 27, 427-438.

Guinness, F.E., Albon, S.D. \& Clutton-Brock, T.M. (1978) Factors affecting reproduction in red deer (Cervus elaphus) hinds on Rhum. J. Reprod. Fert. 54, 325-334.

Henricks, D.M., Dickey, J.F. \& Hill, J.R. (1971) Plasma estrogen and progesterone levels in cows prior to and during estrus. Endocrinology 89, 1350-1355.

Kelly, R.W. \& Challies, C.N. (1978) Incidence of ovulation before the onset of the rut and during pregnancy in red deer hinds. N.Z. JI Zool . 5, 817-819.
Kelly, R.W. \& Moore, G.H. (1977) Reproductive performance in farmed red deer. N.Z. Jl agric. Sci. 11, 179-181.

Kelly, R.W., MeNatty, K.P., Moore, G.H., Ross, D. \& Gibb, M. (1982) Plasma concentrations of $\mathrm{LH}$, prolactin, oestradiol and progesterone in female red deer (Cervus elaphus) during pregnancy. J. Reprod. Fert. 64, 475-483.

Mitchell, B. \& Lincoln, G.A. (1973) Conception dates in relation to age and condition in two populations of red deer in Scotland. J. Zool., Lond. 171, 141-152.

Walton, J.S., McNeilly, J.R., McNeilly, A.S. \& Cunningham, F.J. (1977) Changes in concentrations of follicle-stimulating hormone, luteinizing hormone, prolactin and progesterone in the plasma of ewes during the transition from anoestrus to breeding activity. $J$. Endocr. 75, 127-136.

Received 26 October 1984 